\title{
Development Situation and Countermeasure of Fruit and Vegetable Processing Industry in Guangxi
}

\author{
$\mathrm{Li} \mathrm{Li}^{1,2, a,}$ Jian Sun ${ }^{1,2, \mathrm{~b}^{*},}$ Changbao $\mathrm{Li}^{1,2, \mathrm{c}}$, Dongning Ling ${ }^{1, \mathrm{~d}}$, Xuemei \\ $\mathrm{He}^{1, \mathrm{e},}$ Jinfeng Sheng ${ }^{1, \mathrm{f},}$ Fengjin Zheng ${ }^{1, \mathrm{~g}}$, Guoming Liu $^{1, \mathrm{~h}}$, Fen Liao ${ }^{1, \mathrm{i}}$, Jiemin \\ $\mathrm{Li}^{1, j}$
}

${ }^{1}$ Agro-food Science and Technology Research Institute, Guangxi Academy of Agricultural Sciences, Nanning, Guangxi, 530007

${ }^{2}$ Guangxi Crop Genetic Improvement Laboratory, Nanning, Guangxi, 530007

alili@gxaas.net, ${ }^{\mathrm{b}}$ jiansun@gxaas.net, ${ }^{\mathrm{c}}$ email, ${ }^{\mathrm{d}}$ email, ${ }^{\mathrm{e}}$ email, ${ }^{\mathrm{f}}$ email, ${ }^{\mathrm{g}}$ email, ${ }^{\mathrm{h}}$ email, ${ }^{\mathrm{e}}$ email, ${ }^{\mathrm{j}}$ email,

Keywords: Guangxi; Fruits and Vegetables; Processing; Current Situation of Development

\begin{abstract}
In recent years, agricultural product processing industry in Guangxi has tremendous opportunities with structure adjustment of national agricultural industry and rapid development of agricultural technology. In this review, current situations and main problems of fruit and vegetable processing industry in Guangxi were comprehensively elaborated on the basis of abundant statistical data and field research. Associated factors on fruits and vegetable processing industry were analyzed. Countermeasures for solving main problems of this industry development in Guangxi were also reviewed.
\end{abstract}

\section{Introduction}

Guangxi is located in the southwest of China, the tropic of cancer is across the region and it belongs to subtropical monsoon climate zone, the unique geographical location and climate resources provides good growth conditions for fruit and vegetable [1]. In recent years, with the continuous adjustment of national agricultural structure and the rapid development of agricultural science and technology, Guangxi subtropical fruit and vegetable production and planting area are increasing year by year. In 2014, fruit planting area of Guangxi was 16130000 acres, the total output was 12260000 tons, ranked fourth in the country; the annual output of banana was 256.6 tons, ranking second; litchi annual output was 530600 tons, longan annual output was 50.41 million tons, mango annual output was 217.6 thousand tons, ranking the forefront of the country [2-4]. Vegetable industry has become the second pillar industry of Guangxi agriculture after sugarcane and fruit. [5] In 2014, the planting area of vegetables in the whole region reached 15.24 million acres, accounting for $50 \%$ of the total area of rural economic crops and was up to $24.6 \%$ over the previous year; the total output was 24.1 million tons and was up to $25.4 \%$ over the previous year.

Guangxi has a rich advantage of fruit and vegetable resources, which provide a material basis for promoting the region development of special agricultural. However, the development of agricultural products industry in Guangxi is low, the technology is backward and it has a long-term problem such as low development and utilization level, large waste, low conversion rate, low degree of food quality and weak safety control. In this paper, through a large number of detailed statistical data and field research of fruit and vegetable processing enterprises, we comprehensively and objectively expounded the development status and main problems of fruit and vegetable processing industry in Guangxi. The related factors of fruit and vegetable processing were analyzed and studied. This paper is of great significance to continue to strengthen the research on the key common technologies in the fruit and vegetable processing industry, improve the supporting role of science and technology to the development of fruit and vegetable processing industry, and promote the healthy development of regional economy and regional efficient agricultural industry. 


\section{The Basic Situation of Scientific and Technological Development of Fruit and Vegetable Processing Industry in Guangxi}

The Basic Situation of Fruit and Vegetable Processing Industry. Guangxi promotes the development of fruit and vegetable processing industry closely around the agricultural efficiency, income of farmers and the goal of making rural areas rich. Based on the characteristics of resources, relying on scientific and technological progress, adjust and optimize the product structure, and gradually realize the agricultural products from primary processing to intensive processing and realize the transition from traditional technology to modern technology. At present, Guangxi has initially formed a fruit and vegetable preservation and storage, processing of fruit juice, dried fruit, wine ,canned fruit, jam, and fruit and vegetable active ingredients extraction and functional food processing industries.

The distribution of Guangxi citrus production is in 14 prefecture-level cities, mainly in Guilin, Hezhou, Wuzhou, Liuzhou, Nanning, Yulin, Baise and other places [6]. In the past two years, the market price of citrus has been increasing, which has led to the upsurge of citrus cultivation. The citrus industry in Guangxi has developed rapidly and the area of citrus has expanded again and again. However, Guangxi citrus is mainly sold in the region and the domestic and there are a small number of citrus for exports. With the continuous increase of production scale, citrus fruit market will be saturated, the development of citrus processing industry is imperative [7].

Guangxi is the banana production province, the output ranked second in the country. Bananas are intolerance for storage and postpartum loss is serious [8]. In recent years, the loss rate of postpartum banana was up to nearly 50\%, far higher than China's average rate of consumption of fruits and vegetables $25 \%$ and the percentage of developed countries is $5 \%$. As China's accession to the WTO and the implementation of the ASEAN "0" tariffs, the influx of foreign high-end banana products, the problem that banana is difficult to sell will be further highlighted, which seriously affect the efficiency of banana industry and farmers' income [9]. In all fruit processing, banana processing is relatively backward. Although there are banana wine, banana vinegar, banana jam, banana fruit dry, fried banana crisp, banana powder and other products processing, but the majority of the current processing methods and processed products are difficult to maintain the original color and flavor of banana.

Postharvest preservation technology has been hindering the development of Guangxi mango industry and it is difficult for postpartum preservation and selling which has not yet been resolved [10]. In addition, there are few mango processing enterprises, processing product is single, only mango drinks, preserved fruit, dried mango, mango pickled products and other low-end products, lack of intensive processing products.

Guangxi is pineapple production province and it is mainly distributed in Fangcheng, Qinzhou, Nanning, Chongzuo, Yulin, Baise City [11, 12]. In tropical fruits and vegetables, pineapple processed products are the products with the world's largest sales and pineapple traditional processed products are mainly canned and juice. Pineapple canned was once known as "the king of canned" and pineapple juice is liked by consumers because of its unique health care functions.

Guangxi is the largest persimmon producing areas and it is very rich in resources in 2014, Guangxi persimmon planting area was of 61.8 million acre, the output was 549,400 tons. Guilin of Guangxi has 400 years of persimmon production and processing history, the existing area is 39.4 million mu of persimmon [13]. Persimmon industry has become the important agricultural pillar for Guilin export and increase farmers’ income.

Passion fruits are mainly concentrated in Liuzhou, Qinzhou, Baise, Guilin, Guiping and the North Sea and other hilly areas [14]. At present the development of passion fruits in Qinzhou has formed a resource advantage and it has been incorporated into the regional development layout in Guangxi. In 2010 the sweet corn cultivation area was 79.5 acres, 180,000 tons of fresh fruit production, the processing capacity was 100,000 tons or more. Passion fruit in the government support the rapid development of poverty alleviation projects, has become the fastest growing region of passion fruit, the large-scale cultivation of passion fruit in the region is mainly used for processing fruit juice, and other deep processing of products rarely. 
In recent years, dragon fruit industry is flourish in Guangxi. In 2014, the region has more than 3,000 hectares of cultivated area, the output was 120,000 tons or more, focusing on planting areas in Nanning, Baise, Qinzhou, Beihai, Fangchenggang, Chongzuo. The total areas are more than Guangdong, Guizhou, Yunnan, Fujian and other provinces combined [15, 16]. With the continuous increase of production scale, dragon fruit market will produce saturated fruit, so the development of fruit deep processing is the only way for industrial development. In short, our region deep processing level of dragon fruit, processing capacity is weak, single product variety, low technological content, it is urgent need to increase investment in scientific research and improve production levels and scale.

Guangxi is the main producing areas of litchi. In 2014, the region's planting area was 350 million acre and the annual output was 500,000 tons, the output ranks second in the country. Litchi fruit industry in Guangxi has an important position in many areas and it has become an important source of income for farmers. The distribution area of Guangxi litchi is broad. [17]. Lingshan County of Qinzhou City is known as the "litchi town," the litchi acreage of county is 110.2 million mu, in 2014 the total output was 126,000 tons, the total output value was 460 million RMB. This year total output of lychee is expected to 121,000 tons. At present, more than 10 processing enterprises in Guangxi litchi processing lychee-based, there are a small amount of canned, fruit wine, fruit juice processing. One can imagine that the amount of litchi used for deep processing is very small. In the preservation of lychee after harvest, Guangxi Academy of Agricultural Sciences Institute of Agricultural Products Processing enacted the Guangxi local standards, "Guangxi litchi post-harvest commercialization of technical regulations" in Pingnan, Qinzhou and other places to establish a commercial processing of litchi production line, improve the commodity rate and commodity value of litchi.

The distribution of grape production in Guangxi is 14 prefecture-level cities in more than 30 main producing areas, mainly concentrated in Guilin, Xingan, Quanzhou, Liuzhou, Nanning and other places. In 2014, the area was 40 million acre, the output was more than 20 million tons and the entire grape industry output value was about 1.4 billion. In the past two years, with the perfect of grape cultivation techniques harvest twice one year, production and industry of grape production developed rapidly in Guangxi. Currently grape processing enterprises in the region is still relatively small, limited processing area of cultivated varieties, according to the grape industry development plan and it is bound to promote the expansion of grape processing industry.

Guangxi autumn and winter vegetable production accounts for about $70 \%$ of the total annual, the fall and winter vegetables cultivation has grown into the planting industry after grain, sugar cane and it was the third largest agricultural pillar industries as the main export-oriented vegetable industry. At present, the region's vegetable production has initially formed the western Guangxi alpine cold area of summer-season vegetable commodity production base including southeastern Guangxi, the Youjiang River Valley, along the highway production of winter vegetables commodity production base and northern Guangxi.

\section{The Problems in Guangxi Fruit and Vegetable Processing Industry}

The Fruit and Vegetable Planting and Processing Regional Distribution is Unreasonable, Processing Advantages are not Prominent. Guangxi fruit and vegetable cultivation is mainly based on climate resources distribution, processing and production layout is not reasonable, the distribution of enterprises isn't in accordance with the processing resources layout, excessive concentration or evacuation, resulting in increased costs and difficult to effectively use resources. Some cities and counties production point are too concentrated, even 8-9 points in a county, not far from the point of production, resulting in disguised competition for raw materials, bid up prices, raw material quality picking due to inappropriate decline, causing Chain reaction and resulting in decreased product quality. Some enterprises had to purchase raw materials to maintain production and increased the production costs, while some of the main raw material processing origin does not set up production points and resources have not been effectively used. At the same time in the real management, there are serious departments scattered, multiple management, it is difficult to unify 
the phenomenon.

The Varieties Suitable for Processing is not Enough, Raw Material Base Construction Lag behind. Fruit and vegetable processing industry requires a variety of specialized and stable large-scale, specialized raw material base, in order to ensure the quality of processed products. To citrus, for example, Guangxi has developed a large number of wide-skinned fresh varieties, but for processing with the orange is seriously inadequate. At the same time, the information asymmetry between farmers and processing enterprises, enterprises ignore the planting transmission, farmers do not understand the information on the enterprise, with processing enterprises and farmers are not closely linked to the interests of the raw material base construction and processing enterprises out of touch with each other.

Fruit and Vegetable Processing Enterprises Large-Scale Level and Science and Technology Level is Low. More than $70 \%$ of Guangxi fruit and vegetable processing enterprises are small businesses with an annual output less than 1,000 tons and lack of a strong competitive brand-name enterprises or enterprise groups. The management cost of the small and medium-sized enterprises is higher, and the raw materials are separated from the large enterprises. The utilization rate of the large-scale enterprises is reduced, which leads to the high production cost and the unstable product quality. In addition, the focus of scientific and technological work in China in the field of production, more than $80 \%$ of science and technology funding and research forces into production, post-natal field of scientific research has been neglected, resulting in fruit and vegetable processing technology innovation capacity is low, Is a fundamental lack of technical reserves, making the development of fruit and vegetable processing industry on the level of technological innovation, lack of motivation, technical backwardness.

Comprehensive Utilization is Poor, Single Product and Input Efficiency is Low. The fruit and vegetable processing enterprises in developed countries comprehensively use the raw materials processing from the perspective of the environmental protection and economic benefits and translate by-product into feed or high value-added products. From the peel, fruit seeds and fruit residue in the extraction of dietary fiber, essential oils, pectin substances, tannin, pigment and so on. Such as the United States use of abandoned citrus fruit seeds extract 32\% of the edible oil and $44 \%$ of the protein, the use of grape skin residue extraction grape red pigment from orange peel, apple pomace extract and purification of pectin or citric acid and it has formed large-scale production and achieve better economic benefits.

The Industry Standard System and Quality Control System is not Perfect. Fruit and vegetable standard system is still not perfect in China, the operability and guidance of the standard is not strong and the industry's standards are overlapping. The quality standards of domestic fruit and vegetable processing industry and the international quality standard system derailed, limiting the development of China's fruit and vegetable processing industry. Guangxi fruit and vegetable processing enterprises in the quality control is relatively weak, seriously affecting product quality and participation in international competition, while food safety is worrying. The difference between the product standard, the production process, the management measure and the quality control system and so on with the foreign country, will become the key which restricts the processing industry development, causes the food production from the final product examination primarily control method, transforms for the production entire journey quality control. It is not only the need to participate in international competition, but also the inevitable trend of development of the industry.

\section{The Recommendations}

Guangxi Fruit and Vegetable Post-Harvest Physiological/Pathological Studies and the Promotion of Commercialization Storage and Transportation Fresh Technology. Aiming at the problems of quality deterioration and short storage time during the post-harvest storage and transportation of fruits and vegetables in Guangxi, the endogenous mechanism research platform of postharvest physiology and pathology and storage quality of fruits and vegetables was established. The application of molecular biology, biochemistry, postharvest physiology and Pathology and 
other technical means to carry out research related to the development of new fruit and vegetable compound preservative, preservation of packaging materials, the development of fresh-cut fruits and vegetables in the storage process to slow down the quality of the technical methods to promote Guangxi characteristics of fruits and vegetables commercialization processing technology, The key technology to solve the commercialization of fruits and vegetables production, the establishment of Guangxi characteristics of fruit and vegetable pre-harvest management, post-harvest sorting, grading, cleaning, preservation, packaging, refrigeration and transportation standards.

Improve the Special Fruit and Vegetable Post-Harvest Processing and Distribution System. To promote the commercialization of fruit and vegetable harvest, including promotion of unharmed picking, grading, washing, waxing, labeling, standardized packaging, etc .; carry out joint research to solve the problem of fruit and vegetable preservation technology, improve fruit commodity value and commodity value; At the same time to strengthen the cold storage, refrigerated trucks and other infrastructure construction, fruit harvest into the "cold chain" system, to extend the city time; study electricity, micro-business model under normal temperature short-distance transport of fruits and vegetables storage and preservation technology; established in all areas of professional wholesale Market and information network, strengthen the marketing team, establish, improve the intermediary organizations and market management system and promote the healthy and orderly development and circulation of fruit and vegetable market in Guangxi.

Enhance Echelon Processing and Utilization of Fruit and Vegetable Resources and Improve the Depth and Breadth of Processing Industry. Around the strategic needs of construction of resource-saving society and the implementation of sustainable development, Guangxi special fruit and vegetable resources echelon processing and comprehensive utilization technology are relatively backward, less processing echelon and it is limited to one use and secondary use, low value-added products to carry out Fruit and vegetable processing characteristics and suitability of processing components and interaction of quality control, processing of harmful substances formation and prevention and control, nutrition, molecular design and application of basic research and key technology research and development, breakthrough fruit and vegetable resources echelon processing technology, engineering technology, high Integrated use of technology and functional components of efficient preparation technology and other key technologies, integration of fruit and vegetable resources echelon processing and utilization of technology systems, the development of a number of new technologies, new products, new equipment, enhance the industrial scale and comprehensive benefits.

\section{Acknowledgements}

Fund Project: National Natural Science Foundation of China (31160407, 31560467, 31660589) Public welfare industry (agriculture) research project (201303073)

Guangxi Natural Science Foundation (2014GXNSFAA118110, 2014GXNSFDA118013,
2015GXNSFBA139102)

Guangxi Agricultural Key of Science and Technology Project (201527)

Guangxi Scientific Research and Technology Development Plan Project (Gui Kehe 15104001-23; Gui Kehe 1347004-18; Gui Ke AD16380015)

2015 national introduction of foreign technology and management talent project (GX2015056)

Guangxi Agricultural Sciences Academy basic research cost project (Gui Agricultural Section 2015YT86; Gui Agricultural Section 2015JM14; Gui Agricultural Section 2014YQ05; Gui Agricultural Section 2014JQ04; Gui Agricultural Section 2015JZ75; Gui Agricultural Turn 2016018);

Nanning Scientific Research and Technology Development Plan(20142305)

Nanning Liangqing District Scientific Research and Technology Development Plan (2015G-02)

\section{References}


[1] Wang Fei. Guangxi agricultural product processing industry development situation[J]. Guangxi Agricultural Science, 2014, 29 (5): 88-91.

[2] Huang Yuping. Analysis of the Present Situation of Fruit Industry in Guangxi [J] .Chinese Tropical Agriculture, 2007, (5): 12-13.

[3] Qin Jianli. Guangxi fruit industry status and development of countermeasures[D]. Guangxi University, 2006

[4] Statistical Bureau of Guangxi Zhuang Autonomous Region, Guangxi Statistical Yearbook [M]. Beijing: China Statistics Bureau Press, 2010.

[5] Cai Wang. Guangxi Baise vegetable industry development status and countermeasures [J]. Chinese vegetables, 2012, (3): 1-4.

[6] Guan Jingling. Guangxi citrus processing industry problems and countermeasures[J]. Agricultural Products Processing, 2007,118 (11): 72-75.

[7] Li Ding. Guangxi citrus production and technology status analysis and countermeasures [D]. Guangxi University, 2014

[8] Zheng Wenwu, Yao Jinyan, Peng Hongxiang, Zheng Song. Studies on sustainable development of banana industry in Guangxi[J]. Chinese Agricultural Science Bulletin, 2010, 26 (17): 434-438

[9] Zheng Wenwu, Yao Jinyan, Peng Hongxiang, Zheng Song. Studies on sustainable development of banana industry in Guangxi[J]. Chinese Agricultural Science Bulletin, 2010, 26 (17): 434-438

[10] Li Li, Sheng Jinfeng, Sun Jian, Li Changbao, Zhang Yayuan, Zheng Fengjin. Advances in new technology and comprehensive utilization of mango processing [J] .Food Industry, 2014, 35 (6): 223-227.

[11] Wang Zubin, Shi Lanrong. Status and Development Suggestions of Pineapple Industry in Guangxi [J] .Acta Agricoluvica Sinica, 2015157 (2): 53-55.

[12] Li Zhi, Wang Xiaomei, Fang Weikuan, Ren Hui, Su Weiqiang, Liu Yeqiang, Huang Huiye. Study on the Development of Pineapple Industry in Guangxi [J] .Tropical Agriculture Science, 2015, 35 (4): 82-84.

[13] Deng LiBao, HE Xinhua, Yang ZhiShi, Qin ZhenShi, Lu JiaShi. Study on germplasm resources of persimmon in Guangxi and development and utilization countermeasures [J] .Acta Agronomica Sinica, 2014, 45 (7): 1230-1236.

[14] Zhao Shihai, Wei Shudan. Tianyang. County of Guangxi passion fruit production status and development[J]. Anhui Agricultural Sciences, 2015, 43 (22): 309-310.

[15] Xu Hui, Wang Qiuling, Wei Gang, Mo Jianguang. Research on the Health Effects of Hylocereus undatus and Its Research Progress [J] Guangxi Academy of Sciences, 2010,26 (3): 383-385.

[16] Gao Long, GIS-based study on climatic division of Guangxi dragon fruit cultivation [D]. Guangxi University, 2014

[17] Yao Jinyan, Long Xing, Peng Hongxiang, Zhu Jianhua. Study on postharvest biology of litchi and its development in Guangxi [J] Guangxi Agricultural Sciences, 2010, 41 (5): 475-478. 